2008

\title{
Silencing Expression of the Defensin, Varisin, in Male Dermacentor variabilis by RNA Interference Results in Reduced Anaplasma Marginale Infections
}

Katherine M. Kocan

Jose de la Fuente

Raul Manzano-Roman

Victoria Naranjo

Wayne L. Hynes

Old Dominion University, whynes@odu.edu

See next page for additional authors

Follow this and additional works at: https://digitalcommons.odu.edu/biology_fac_pubs

Part of the Entomology Commons, and the Parasitology Commons

\section{Repository Citation}

Kocan, Katherine M.; de la Fuente, Jose; Manzano-Roman, Raul; Naranjo, Victoria; Hynes, Wayne L.; and Sonenshine, Daniel E., "Silencing Expression of the Defensin, Varisin, in Male Dermacentor variabilis by RNA Interference Results in Reduced Anaplasma Marginale Infections" (2008). Biological Sciences Faculty Publications. 104.

https://digitalcommons.odu.edu/biology_fac_pubs/104 
Authors

Katherine M. Kocan, Jose de la Fuente, Raul Manzano-Roman, Victoria Naranjo, Wayne L. Hynes, and Daniel E. Sonenshine 


\section{Editorial Manager(tm) for Experimental and Applied Acarology \\ Manuscript Draft}

\section{Manuscript Number: APPA264R1}

Title: Silencing expression of the defensin, varisin, in male Dermacentor variabilis by RNA interference results in reduced Anaplasma marginale infections.

Article Type: Special Issue - Diseases

\section{Section/Category:}

Keywords: defensin, varisin, RNA interference, Dermacentor variabilis, Anaplasma marginale.

Corresponding Author: Prof. D.E. Sonenshine,

Corresponding Author's Institution: Old Dominion University

First Author: Katherine M Kocan, Ph. D

Order of Authors: Katherine M Kocan, Ph. D; Jose de la Fuente, Ph. D; Raul Manzano-Roman, Ph. D; Victoria Naranjo, Ph. D; Wayne L Hynes, Ph. D; D.E. Sonenshine

Manuscript Region of Origin:

Abstract: Antimicrobial peptides, including defensins, are components of the innate immune system in ticks that have been shown to provide protection against both gram-negative and gram-positive bacteria. Varisin, one of the defensins identified in Dermacentor variabilis, was shown to be produced primarily in hemocytes but transcript levels were also upregulated in midguts and other tick cells. In this research, we studied the role of varisin in the immunity of ticks to the gram-negative cattle pathogen, Anaplasma marginale.

Expression of the varisin gene was silenced by RNA interference (RNAi) in which male ticks were injected with varisin dsRNA and then allowed to feed and acquire A. marginale infection on an experimentallyinfected calf. Silencing expression of varisin in hemocytes, midguts and salivary glands was confirmed by real time RT-PCR. We expected that silencing of varisin would increase A. marginale infections in ticks, but the results demonstrated that bacterial numbers, as determined by an A. marginale msp4 quantitative PCR, were significantly reduced in the varisin-silenced ticks. Furthermore, colonies of $A$. marginale in ticks used 
for RNAi were morphologically abnormal from those seen in elution buffer injected control ticks. The colony shape was irregular and in some cases the A. marginale appeared to be free in the cytoplasm of midgut cells. Some ticks were found to be systemically infected with a microbe that may have been related to the silencing of vanisin. This appears to be the first report of the silencing of expression of a defensin in ticks by RNAi that resulted in reduced A. marginale infections.

Response to Reviewers: We have revised the manuscript extensively in accordance with the recommendations of the reviewers. In most cases, we accepted the reviewer's suggestions for rewriting the text and substituted those revisions as recommended. There is not sufficient space in this comment box to detail every change that was made to every specific comment, but we did attempt to address all comments from the several reviewers and incorporate them. 
2 Silencing expression of the defensin, varisin, in male Dermacentor variabilis by RNA

3 interference results in reduced Anaplasma marginale infections

4

5 Katherine M. Kocan ${ }^{1}$, José de la Fuente ${ }^{1,2}$, Raúl Manzano-Roman ${ }^{1}$, Victoria Naranjo ${ }^{2}$, Wayne L.

6 Hynes $^{3}$ and Daniel E. Sonenshine ${ }^{3}$.

7

$8{ }^{1}$ Department of Veterinary Pathobiology, Center for Veterinary Health Sciences, Oklahoma

9 State University, Stillwater, OK, USA.

10 Instituto de Investigación en Recursos Cinegéticos IREC (CSIC-UCLM-JCCM), Ronda de

11 Toledo s/n, 13005 Ciudad Real, Spain.

12. ${ }^{3}$ Department of Biological Sciences, Old Dominion University, Norfolk, VA, USA.

13

14 Corresponding Author:

15 Daniel E. Sonenshine, Ph.D.

16 Department of Biological Sciences

17 Old Dominion University

18. Norfolk, VA 23529-0266

19 Telephone: (757) 683-3612

20 FAX: (757) 683-5283

21 E-mail: dsonensh@odu.edu 


\section{Abstract}

2 Antimicrobial peptides, including defensins, are components of the innate immune system in

3 ticks that have been shown to provide protection against both gram-negative and gram-positive

4 bacteria. Varisin, one of the defensins identified in Dermacentor variabilis, was shown to be

5 produced primarily in hemocytes but transcript levels were also expressed in midguts and other

6 tick cells. In this research, we studied the role of varisin in the immunity of ticks to the gram-

7 negative cattle pathogen, Anaplasma marginale. Expression of the varisin gene was silenced by

8 RNA interference (RNAi) in which male ticks were injected with varisin dsRNA and then

9 allowed to feed and acquire $A$. marginale infection on an experimentally-infected calf.

10 Silencing expression of varisin in hemocytes, midguts and salivary glands was confirmed by

11 real time RT-PCR. We expected that silencing of varisin would increase $A$. marginale

12 infections in ticks, but the results demonstrated that bacterial numbers, as determined by an $A$.

13 marginale msp4 quantitative PCR, were significantly reduced in the varisin-silenced ticks.

14 Furthermore, colonies of $A$. marginale in ticks used for RNAi were morphologically abnormal

15 from those seen in elution buffer injected control ticks. The colony shape was irregular and in

16 some cases the $A$. marginale appeared to be free in the cytoplasm of midgut cells. Some ticks

17 were found to be systemically infected with a microbe that may have been related to the

18 silencing of varisin. This appears to be the first report of the silencing of expression of a

19 defensin in ticks by RNAi that resulted in reduced $A$. marginale infections.

21 Keywords: defensin, varisin, RNA interference, Dermacentor variabilis, Anaplasma 22 marginale. 
Ticks transmit a greater variety of pathogens than any other group of hemotophagous

3 arthropods (Sonenshine 1993). In ticks, the midgut is the first site of exposure to a wide variety

4 of hemoparasites that may be ingested with the bloodmeal. Some of these hemoparasites are

5 either not infective for ticks and rapidly digested or cleared by the innate tick immune system.

6 Others infect midgut epithelial cells where they multiply and subsequently infect other tissues

7 including the salivary glands. Transmission may occur when the tick is ingested by the

8 vertebrate host or from salivary glands via the saliva to vertebrate hosts when the ticks feeds

9 again. Tick-borne pathogens have apparently co-evolved with ticks for their mutual survival

10 because, while pathogens undergo considerable multiplication in ticks, these infections do not

11 appear to be detrimental to tick feeding or their biology (Kocan et al. 1992a; Kocan et al. 2005;

12 Sonenshine et al. 2005).

13 Among the various tick-borne pathogens, those belonging to the genus Anaplasma

14 (Rickettsiales: Anaplasmataceae) are obligate intracellular organisms found exclusively within

15 parasitophorous vacuoles in the cytoplasm of both vertebrate and tick host cells (Kocan 1986;

16 Dumler et al., 2001). The type species, $A$. marginale, causes the economically important cattle

17 disease, anaplasmosis, with Dermacentor variabilis comprising one of the main tick vectors of

18 this pathogen in the U.S. (Kocan et al., 2004).

19 While the molecular relationship between ticks and pathogens is not well understood,

20 these molecular interactions may enhance or be necessary for tick and pathogen biology (de la

21 Fuente et al. 2007a). In this emerging area of research, initial studies of tick host cell response

22 to Anaplasma infection revealed genes that are differentially expressed in response to pathogen

23 infection. These genes, therefore may be necessary for and facilitate pathogen infection, 
1 multiplication and transmission (i.e. receptors) or limit infections that favor tick survival (de la

2 Fuente et al. 2001; 2005; 2007 a, b; Manzano-Roman et al. 2007).

3 One component of innate immune systems of eukaryotic organisms are the small

4 cationic peptides known as defensins, which have been identified in a wide range of species

5 ranging from the simplest invertebrates to mammals, as well as plants (Gillespie et al. 1997).

6 Among invertebrates, the most completely characterized defensins contain 6 cysteines and

7 provide immunity against gram-positive bacteria (Ganz and Lehrer 1994; Fogaca et al. 2004). In

8 insects, these defensins were found to be expressed primarily in fat body and midgut epithelial

9 cells (Hoffman and Hetru, 1992; Boulanger et al. 2002).

10 Defensins have been identified in a variety of ixodid ticks, including D. variabilis (Johns

11 et al. 2001a; Ceraul et al. 2003), Ixodes scapularis (Hynes et al. 2005), Amblyomma

12 americanum (Todd et al. 2007), A. hebraeum (Lai et al. 2004) and R. microplus (Fogaça et al.

13 2004; Tsuji et. al. 2007). While defensins have clearly been shown to be expressed in tick

14 hemocytes (Johns et al. 2000; 2001a), they were also found to be expressed or at least

15 transcribed in midguts and other tick tissues in the soft tick Ornithodoros moubata (Nakajima et

16 al. 2002) and the hard ticks Amblyomma americanum and Ixodes scapularis (Todd et al. 2007;

17 Hynes et al. 2005). Tick defensins were shown to be involved in protection against a wide

18 range of organisms such as Micrococcus luteus in Dermacentor variabilis (Johns et al. 20001a)

19 or Escherichia coli and Staphylococcus aureus as demonstrated in A. hebraeum (Lai et al.

20 2004). Upregulation of a defensin occurred in response to challenge-exposure of $D$. variabilis

21 with the gram-negative rickettsia, Rickettsia montanensis, fed to ticks via capillary tubes

22 (Ceraul et al. 2007). In addition, defensins were also found to provide immunity against the

23 protozoan parasites, Babesia equi, B. gibsoni and B. microti (Tsuji et al. 2007). This collective 
1 research suggests that defensins contribute to the elimination or modulation of microbes to

2 which ticks are exposed.

3 In this study we hypothesized that expression of varisin would provide protection in $D$.

4 variabilis against infection by the gram-negative $A$. marginale. RNA interference (RNAi) was

5 used to silence the varisin gene in male D. variabilis, after which the ticks were allowed to feed

6 on an A. marginale-infected calf to acquire bacteria. Varisin gene silencing was confirmed by

7 real time RT-PCR and $A$. marginale abundance was determined by use of a quantitative PCR

8 assay for $A$. marginale msp4 gene. Surprisingly, the results derived from this research were

9 contrary to our hypothesis and demonstrated that silencing of varisin resulted in significantly

10 reduced $A$. marginale numbers. Further studies are needed to determine whether defensin may

11 be necessary for the development of $A$. marginale in ticks.

Materials and Methods

13 Ticks.

Dermacentor variabilis males were purchased from a laboratory colony maintained at the Oklahoma State University (OSU), Tick Rearing Facility, Stillwater, OK. Larvae and nymphs were fed on rabbits and male ticks derived from the engorged nymphs were used for these studies. Male ticks were used for these studies because they become persistently infected

18 with $A$. marginale and the pathogen's developmental cycle has been well described in the 19 intrastadial cycle. In addition intrastadial studies avoid the possible influence of molting. Off20 host ticks were maintained in a $12 \mathrm{hr}$ light: $12 \mathrm{hr}$ dark photoperiod at $22-25^{\circ} \mathrm{C}$ and $95 \%$ relative 21 humidity.

22 Infection of ticks with A. marginale.

23 For infection of ticks with $A$. marginale, male $D$. variabilis ticks injected with either 24 varisin dsRNA or elution buffer alone were allowed to acquire bacteria during feeding 
1 (acquisition feeding, AF). Acquisition was done by feeding the ticks for seven days on a

2 splenectomized calf that was experimentally-infected with the Virginia isolate of $A$. marginale

3 which was shown previously to be infective and transmissible by ticks (Kocan et al. $1992 \mathrm{a}, \mathrm{b}$ )

4 when the ascending percent parasitized erythrocytes (PPE) was 3-4\%. The ticks were then

5 removed and maintained off-host for 4 days, after which they were allowed to feed for seven

6 days on a sheep to allow for development of $A$. marginale in tick salivary glands and

7 transmission (transmission feeding, TF). Two days after infestation of the sheep all unattached

8 ticks were removed and discarded. All ticks were removed after 7 days of feeding and held in

9 the humidity chamber for four days. The calf and sheep were housed at the OSU Center for

10 Veterinary Health Sciences, Laboratory Animal Resources with a protocol approved by OSU

11 Institutional Animal Care and Use Committee.

12 RNA interference in ticks.

13 Oligonucleotide primers homologous to D. variabilis defensin and containing T7

14 promoters for in vitro transcription and synthesis of dsRNA (DEFT75: 5'-

15 TAATACGACTCACTATAGGGTACTATGCGCGGACTTTGCATCTGC and DEFT733: 5'-

16 TAATACGACTCACTATAGGGTACTTACGTCGACAAAGCGCTTCGG) were synthesized to

17 amplify tick defensin. RT-PCR and dsRNA synthesis reactions were performed as described

18 previously (de la Fuente et al., 2006 a, b), using the Access RT-PCR system (Promega) and the

19 Megascript RNAi kit (Ambion, Austin, TX, USA). The purified dsRNA was quantified by

20 spectrometry (BioRad SMART SPEC 3000).

21 In order to test the effect of injection with varisin dsRNA on development of $A$.

22 marginale in male $D$. variabilis, 20 ticks per group were injected in the lower right quadrant of

23 the ventral surface of the exoskeleton with approximately $0.4 \mu$ l of varisin dsRNA $\left(5 \times 10^{10}\right.$ -

$245 \times 10^{11}$ molecules per $\mu \mathrm{l}$ ) (de la Fuente et al., 2006a; 2006b). The exoskeleton was first pierced 
1 with the tip of a $30 \mathrm{~g}$ needle to create an opening and then the dsRNA was injected through this

2 opening into the hemocoel using a Hamilton ${ }^{\circledR}$ syringe fitted with a $33 \mathrm{~g}$ needle. Twenty ticks

3 were injected with $D$. variabilis subolesin dsRNA to serve as positive controls (de la Fuente et

4 al. 2006a, 2006b) or elution buffer used in the final step of purification of dsRNA (10 mM Tris-

$5 \mathrm{HCl}, \mathrm{pH} 7,1 \mathrm{mM}$ EDTA) alone to serve as negative controls. The ticks were held in a humidity

6 chamber for $24 \mathrm{hr}$ after which they were allowed to feed on an experimentally infected calf.

7 Analysis of tick attachment and feeding.

Tick attachment was evaluated during AF and TF as the ratio of attached ticks $48 \mathrm{hrs}$

9 after infestation on the calf to the total number of ticks. Tick mortality was evaluated as the ratio

10 of dead ticks after feeding on the calf (AF) or the sheep (TF) to the total number of fed ticks.

11 Tick attachment and mortality were compared between dsRNA and elution buffer-injected ticks

12 by $\chi 2$-test as implemented in Mstat $4.01(\alpha=0.01)$.

13 Dissection of tick tissues and hemolymph collection for determination of $\mathbf{m R N A}$ levels and

14 A. marginale infections.

15 Midguts were dissected from 5 ticks after AF and stored in RNAlater (Ambion) for

16 extraction of DNA and RNA using Tri-Reagent (Sigma) according to manufacturer's

17 instructions to determine the $A$. marginale levels by msp4 quantitative PCR (de la Fuente et al.,

18 2001) and to confirm gene expression silencing by real-time RT-PCR as described below. After

19 TF, salivary glands and guts were dissected from 5 ticks from each group and processed for

20 RNA and DNA studies as described. Tick tissues were processed and analyzed individually.

21 Midguts and salivary glands were also collected from another 5 ticks and fixed for microscopy

22 studies (see following section).

23 To assess the effect of defensin RNAi on the expression of defensin in tick hemocytes,

2450 male $D$. variabilis ticks were injected with defensin dsRNA or elution buffer alone as 
1 described above. Injected ticks were allowed to feed on a calf for three days after which they

2 were removed with forceps. Hemolymph was collected from the severed legs of two groups of

325 ticks each from both the RNAi and control groups using finely drawn $100 \mu$ glass collecting

4 micropipets (VWR International, Suwanee, GA), and dispensed into $30 \mu 1$ of sterile phosphate-

5 buffered saline (PBS). Total RNA was extracted and the expression of defensin was quantified

6 by real time RT-PCR as described below.

7 Real-time reverse transcription (RT)-PCR analysis.

8 Total RNA was extracted from 5 individual uninfected and $A$. marginale-infected male

9 D. variabilis guts and salivary glands and from two hemolymph pools from 25 ticks each using

10 TriReagent (Sigma) according to manufacturer's instructions. Two primers were synthesized

11 based on the sequences of $D$. variabilis defensin (Genbank accession number AY181027;

12 Ceraul et al. 2003) (DvDEFEN-5: TCTGGCATCATCAAGCAGAC and DvDEFEN-3:

13 CTGCAAGTATTCCGGGGTTA) and used for real-time RT-PCR analysis of mRNA levels in

14 uninfected and $A$. marginale-infected ticks. Subolesin mRNA levels were determined as

15 described previously (de la Fuente et al. 2006b). Real-time RT-PCR was done using the

16 QuantiTec SYBR Green RT-PCR kit (Qiagen, Valencia, CA, USA) and a Bio-Rad iQ5 thermal

17 cycler (Hercules, CA, USA) following manufacturer's recommendations. Amplification

18 - efficiencies were normalized against tick $\beta$-actin (forward primer: $5^{\prime}$ -

19 GAGAAGATGACCCAGATCA; reverse primer: 5'- GTTGCCGATGGTGATCACC) using

20 the comparative $\mathrm{Ct}$ method (de la Fuente et al., 2007 a,b). mRNA levels were compared

21 between infected and uninfected ticks by Student's $\mathrm{t}$-Test $(\mathrm{P}=0.05)$ and average mRNA levels

22 were used to calculate percent silencing in dsRNA-injected ticks with respect to elution buffer-

23 injected controls.

24 Quantification of $A$. marginale infections in ticks by PCR. 
1 A. marginale infections in dsRNA injected and control ticks were determined by a major

2 surface protein 4 (msp4) quantitative PCR as reported previously (de la Fuente et al. 2001).

3 Total DNA was extracted from 5 individual $A$. marginale-infected and uninfected male $D$.

4 variabilis collected after TF using TriReagent (Sigma) according to manufacturer's instructions.

5 A. marginale infection levels in tick midguts and salivary glands were compared between

6 dsRNA and saline injected ticks by Student's t-test $(\mathrm{P}=0.05)$.

7 Light microscopy studies of $\boldsymbol{D}$. variabilis gut and salivary glands.

8 Ticks were cut in half, separating the right and left halves, and fixed in $2 \%$

9 glutaraldehyde in $0.2 \mathrm{M}$ sodium cacodylate buffer ( $\mathrm{pH}$ 7.4). Tick halves were then post-fixed in

$10 \quad 0.2 \mathrm{M}$ sodium cacodylate buffer ( $\mathrm{pH} 7.4)$, dehydrated in a graded series of ethanol and

11 embedded in epoxy resin (Kocan et al. 1980). Thick sections $(1.0 \mu \mathrm{m})$ were cut with an

12 ultramicrotome and stained with Mallory's stain (Richardson et al., 1960). Photomicrographs

13 were recorded using a light microscope equipped with a 3-chip digital camera.

\section{RESULTS}

15 Tick attachment, feeding and $A$. marginale calf infection levels during tick feeding.

16 Tick attachment and survival after AF (95\% attachment and $85 \%$ survival) and TF (95\%

17 attachment and $89 \%$ survival) did not appear to be affected by injection of ticks with varisin

18 dsRNA when compared to the elution buffer (100\% and $97 \%$ attachment and $88 \%$ and $91 \%$

19 survival after AF and TF, respectively; $a>0.01)$ and subolesin-injected controls $(95 \%$ and $100 \%$

20 attachment and $88 \%$ and $90 \%$ survival after AF and TF, respectively; $\alpha>0.01$ ). The PPE during

21 tick feeding on the calf experimentally infected with the Virginia isolate of $A$. marginale ranged

22 from $4.8 \%$ to $35.9 \%$.

23. Silencing of expression of varisin in tick tissues. 
2 determined by real-time RT-PCR (Table 1). Silencing of the varisin gene by RNAi was also

3 confirmed by real time RT-PCR in tick midguts after AF (89\%) and in the midguts (97\%) and

4 salivary glands (57.9\%) after TF as compared with the elution buffer-injected controls (Table

5 1). For the positive control ticks injected with subolesin dsRNA, silencing in midguts after AF

6 was $90.0 \%$; after TF, it was $99.7 \%$ in midguts and $99.4 \%$ in salivary glands (Table 1 ).

7 The effect of varisin RNAi on $A$. marginale infections in male $D$. variabilis.

Levels of $A$. marginale tick infections, as determined by a msp 4 quantitative PCR and analyzed by Student's t-test, were significantly reduced in tick midguts after AF and in salivary glands after TF as compared with the elution buffer-injected controls $\left({ }^{*} \mathrm{P} \leq 0.05\right)$ (Table 2).

Although not statistically significant, $A$. marginale infection levels were also lower in tick midguts after TF as compared with the elution buffer-injected controls (Table 2). Reduction of A. marginale levels after RNAi of the subolesin gene (positive control) was statistically significant only in salivary glands collected from transmission fed ticks (Table 2). Expression levels of varisin in A. marginale-infected and uninfected $D$. variabilis Varisin mRNA levels were higher after TF in the midguts of uninfected ticks as compared to infected ticks $(\mathrm{P}=0.02)$. In contrast, varisin levels were significantly higher in the salivary glands from $A$. marginale infected ticks $(\mathrm{P}=0.05)$ as compared to the salivary glands

19 from uninfected ticks (Table 3).

Light microscopic changes in ticks injected with varisin dsRNA.

Morphologic changes were observed in the colonies of $A$. marginale in tick midguts ticks. While typical large, round colonies of $A$. marginale, were observed in the control ticks, colonies in the varisin dsRNA injected ticks were irregular in shape (Figs. 1 A and B). Some 
1 tick midgut cells appeared to contain A. marginale free in the cytoplasm rather than within the

2 parasitophorous vacuole (Fig. 1B, arrowheads). Hemocytes in the varisin dsRNA injected ticks

3 were degranulated as compared with those from the controls (Figs. 1 C and D). Two of these

4 ticks appeared to be systemically infected with microbes of unknown identity. Large numbers

5 of these organisms were observed in most tissues, including midguts (Fig. 1E) and

6 spermatogonia (Fig 1F). Similar systemic microbial infections were not observed in the elution

7 buffer- or subolesin dsRNA injected controls (data not shown).

\section{Discussion}

Ticks are exposed to a wide variety of organisms from mammalian hosts during their extended feeding periods. While some of these organisms are not infective for ticks, others

11 infect tick midguts, where they undergo development and are subsequently transmitted to other

12 hosts during feeding or when the ticks are ingested by the host. During attachment and blood

13 feeding, tick genes express a variety of proteins and peptides involved in the innate immune

14 response that function to inhibit microbial infection, as well as mitigating the oxidative stress

15 and the toxic byproducts (e.g., heme) of hemoglobin digestion. These proteins may include

16 several stress reducing proteins such as glutathione-S-transferases (Dreher-Lesnick et al. 2006),

17 protease inhibitors, lectins and others (Lehane et al. 1997; Zhou et al. 2006, Rudenko et al.,

18 2005). In addition, anti-microbial peptides in ticks have been reported to be upregulated in

19 response to microbial challenge. For example, lysozyme was found to be upregulated in tick

20 hemolymph after challenge-exposure with $E$. coli (Simser et al. 2004).

21 An example of the ability of ticks to rapidly eliminate noninfective organisms was

22 demonstrated by de la Fuente et al. (2001) in which $D$. variabilis males that fed for 7 days on

23 calves with $>70 \%$ erythrocytes infected with a non-tick transmissible isolate (Florida isolate) of 
1 A. marginale were found to be clear of $A$. marginale DNA four days after being removed from

2 the infected calf.

3 The small cationic peptides, defensins, are a notable part of the innate response in ticks.

4 Defensins were found to be upregulated in response to challenge with $B$. burgdorferi or gram

5 positive bacteria (Johns et al. 2001b; Ceraul et al. 2003; Nakajima et al. 2001, 2002). Upregulation of tick defensins has also been reported in response to gram negative bacteria such

7 as the intracellular rickettsia, $R$. montanensis (Ceraul et al. 2007) and to protozoan pathogens

8 such as Babesia species (Tsuji et al. 2007). The reports cited above suggest that ticks are able to

9 eliminate or at least curtail most microbial infections to which they are exposed.

In this research we tested the hypothesis that one of the defensins identified in $D$. variabilis, varisin, was involved in the tick innate immune response in response to infection

12 with the gram negative cattle pathogen, $A$. marginale. If the results supported our hypothesis,

13 silencing the expression of the varisin gene by RNAi would have resulted in greater numbers of 14 A. marginale in the ticks. While expression of varisin was confirmed to be silenced in the midguts and hemocytes of the male $D$. variabilis after $\mathrm{AF}$ and in the midguts and salivary 16 glands after TF, both sites of varisin expression (Johns et al. 2001a; Ceraul et al. 2003), the 17 results of these studies were opposite to those expected. Silencing of varisin resulted in significantly lower numbers of $A$. marginale organisms in these male ticks. These results

19 suggested that defensin may play a role in $A$. marginale infection and multiplication in $D$. variabilis in a manner different than we had expected. Interestingly, varisin appeared down-

21 regulated in the gut of infected ticks but it was up-regulated in the salivary glands after TF.

22 These results suggest a mechanism by which $A$. marginale may down-regulate varisin 23 expression to establish infection in the guts while in the salivary glands varisin may plays a role 24 in pathogen infection and multiplication. 
Although these studies were not designed to quantify morphologic changes, the

2 appearance and integrity of the $A$. marginale colonies in midgut epithelial cells suggested

3 an impact of varisin RNAi on parasite development. Within host cells, $A$. marginale

4 develop within a parasitophorous vacuole (called colonies) which is uniformly round.

5 However, in ticks in which varisin was silenced by RNAi, A. marginale colonies were

6 highly irregular and some organisms appeared to be free within the cell cytoplasm.

Another explanation for the reduction in the numbers of $A$. marginale organisms

8 is that it may have resulted from divergent changes in the levels of expression of off-target

9 genes (Scacheri et al. 2004; Ma et al. 2006). At least in mammalian systems, RNAi is

10 known to induce unexpected and divergent changes in the levels of expression of off-target

11 genes (Schaceri et al. 2004). Specifically, in some mammalian systems, RNAi resulted in

12 global upregulation of the interferon system with unexpected consequences (Siedz et al.

13 2003). Similarly, as reported for salps 16 and other tick genes (Sukumaran et al., 2006; de

14 la Fuente et al. 2007c), defensin expression may be manipulated by the pathogen to aid in

15 its multiplication by an as yet undefined mechanism. Alternatively, RNAi treatment may

16 have affected other physiological processes that modified tick susceptibility to infection by

17 other pathogens. Finally, due to the redundant gene function of other defensin genes

18 (Ceraul et al., 2007), the possibility that silencing of the varisin gene targeted in these

19 studies may not be sufficient to suppress all defensin response in ticks should be

20 considered.

21 Interestingly, other effects were noted in ticks after varisin RNAi. We observed

22 that two of five ticks appeared to have a systemic infection with an unknown microbe.

23 Although the microbes were seen in most tissues, infections were most notable in the

24 midgut and testis. However, similar systemic infections were not seen in sections of five 
1 control ticks (elution buffer- or subolesin dsRNA-injected ticks). While the microscopy

2 studies herein were not designed to be quantitative, this observation provided evidence that

3 the silencing of varisin by RNAi may have been related to extensive multiplication of a

4 microbe other than A. marginale. Further studies are needed to define the relationship

5 between other microbes and $A$. marginale. We also noted degranulation of hemocytes in

6 the ticks injected with varisin dsRNA. However, whether either of these observations were

7 directly related to varisin knockdown is not known.

8 The results reported here illustrate the utility of RNAi as a powerful tool for studying the

9 effect of gene silencing in ticks as reported previously (de la Fuente et al. 2007c). However, the

10 effect of gene silencing may be indirect rather than direct due to off-target RNAi effects and

11 may be limited by our understanding of the molecular biology of tick-pathogen interactions.

12 Since ticks and the pathogens they transmit have co-evolved molecular interactions to assure

13 their survival, these interactions are likely to involve loci in both the pathogen and the tick.

14 Further studies are needed to fully explore the impact of defensins on the infection and

15 development of $A$. marginale in ticks.

16 Acknowledgments

17 This research was partially supported by the Oklahoma Agricultural Experiment Station (project

18 1669), the Walter R. Sitlington Endowed Chair for Food Animal Research (K. M. Kocan,

19 Oklahoma State University), Pfizer Animal Health, Kalamazoo, MI, USA, the Junta de

20 Comunidades de Castilla-La Mancha, Spain (project 06036-00 ICS-JCCM), and Ministry of

21 Science and Education (MEC), Spain (project AGL2005-07401). Dr. Raúl Manzano-Roman

22 was funded by Ministerio de Educación y Ciencia, Spain. V. Naranjo was founded by

23 Consejería de Educación, JCCM, Spain. Support, in part, is gratefully acknowledged by a 
1 grant from the National Science Foundation, IBN 0212901 (Hynes \& Sonenshine) and a grant

2 from the National Research Fund for Tick-borne Diseases (Hynes \& Sonenshine).

3 References

4 Boulanger N, Munks RJ, Hamilton, JV, Vovelle F, Brun R, Lehane MJ, Bulet P (2002)

5 Epithelial innate immunity. A novel antimicrobial peptide with antiparasitic activity in the

6 blood-sucking insect Stomoxys calcitrans. J Biol Chem 277: 49921-49926

7 Ceraul SM, Sonenshine DE, Ratzlaff RE, HynesWL (2003) An arthropod defensin expressed

8 by the hemocytes of the American dog tick, Dermacentor variabilis (Acari: Ixodidae).

$9 \quad$ Insect Biochem Mol Biol 33:1099-1103

10 Ceraul SM, Dreher-Lesnick S, Gillespie JJ, Sayeedur Rahman M, Azad AF (2007) A new tick

11 defensin isoform and antimicrobial gene expression in response to Rickettsia montanensis

12 challenge. Infect Immun 75:1973-1983

13 de la Fuente J, Garcia-Garcia JC, Blouin EF, Kocan KM (2001) Major surface protein 1a effects

14 tick infection and transmission of the ehrlichial pathogen Anaplasma marginale. Int J

$15 \quad$ Parasitol 31:1705-1714

16 de la Fuente J, Ayoubi P, Blouin EF, Almazán C, Naranjo V, Kocan KM (2005) Gene

17 expression profiling of human promyelocytic cells in response to infection with Anaplasma

18 phagocytophilum. Cell Microbiol 7:549-559

19 de la Fuente J, Almazán C, Blouin EF, Naranjo V, Kocan KM. (2006a) Reduction of tick

20 infections with Anaplasma marginale and A. phagocytophilum by targeting the tick

21 protective antigen subolesin. Parasitol Res 100:85-9.

22 de la Fuente J, Almazán C, Blas-Machado U, Naranjo V, Mangold AJ, Blouin EF, Gortazar C,

23 Kocan KM. (2006b) The tick protective antigen, 4D8, is a conserved protein involved in

24 modulation of tick blood ingestion and reproduction. Vaccine 24:4082 - 4095 
1 de la Fuente J, Blouin EF, Manzano-Roman R, Naranjo V, Almazán C, Pérez de la Latra JM,

2 Zivkovic Z, Jongejan F, Kocan KM (2007a) Functional genomic studies of tick cells in

3 response to infection with the cattle pathogen, Anaplasma marginale. Genomics 90: 712-

$4 \quad 722$

5 de la Fuente J, Manzano-Roman R, Blouin EF, Naranjo V, Kocan KM (2007b) Sp110

6 transcription is induced and required by Anaplasma phagocytophilum for infection of human

$7 \quad$ promyelocytic cells. BMC Infectious Diseases 7: 110

8 de la Fuente J, Kocan KM, Almazán C, Blouin EF (2007c) RNA interference for the study and

9 genetic manipulation of ticks. Trends Parasitol 23:427-433

10 Dreher-Lesnick SM, Mulenga A, Simser JA, Azad AF (2006) Differential expression of two

11 glutathione S-transferases identified from the American dog tick, Dermacentor variabilis.

12 Insect Mol Biol 15:445-53

13 Dumler JS, Barbet AC, Bekker CPJ, Dasch GA, Palmer GH, Ray SC, Rikihisa Y, Rurangirwa

14 FR (2001) Reorganization of the genera in the families Rickettsiaceae and Anaplasmataceae

15 in the order Rickettsiales: unification of some species of Ehrlichia with Anaplasma,

16 Cowdria with Ehrlichia and Ehrlichia with Neorickettsia, descriptions subjective synonyms

17 of Ehrlichia phagocytophila. Int J Sys Evol Microbiol 51:2145-2165

18 Fogaca AC, Lorenzini DM, Kaku LM, Esteves E, Bulet P, Daffre S (2004) Cysteine-rich

19 antimicrobial peptides of the cattle tick Boophilus microplus: isolation, structural

20 characterization and tissue expression profile. Develop Comp Immunol 28:191-200

21 Ganz T, Lherer R I (1994) Defensins. Curr Opin Immunol 6:584-589

22 Gillespie JP, Kanost MR, Trenczek T (1997) Biological mediators of insect immunity. Ann Rev

23 Entomol 42:611-643 
1 Hoffmann JA, Hetru C (1992) Insect defensins: inducible antibacterial peptides. Immunol.

2 Today $13: 411-415$

3 Hynes WL, Ceraul SM, Todd SM, Seguin KC, Sonenshine DE (2005) A defensin-like gene

4 expressed in the black-legged tick, Ixodes scapularis. Med Vet Entomol 19:339-344

5 Johns R, Sonenshine DE, Hynes WL (2000) Tick immunity to microbial infections: anti-

6 bacterial peptides or proteins in the hemolymph of the hard tick Dermacentor variabilis

7 (Acari: Ixodidae). Acarology Proc 10th Internatl Congr P, p 638 - 644. Canberra, Australia

8 Johns.R, Sonenshine DE, Hynes WL (2001a) Identification of a defensin from the hemolymph

9 of the American dog tick, Dermacentor variabilis. Insect Biochem Mol Biol 31:857 - 865

10 Johns R, Ohnishi J, Broadwater A, Sonenshine DE, deSilva A. Hynes WL (2001b) Contrasts in

11 tick immune responses to Borrelia burgdorferi challenge: immunotolerance in Ixodes

12 scapularis (L.) versus immunocompetence in Dermacentor variabilis. J Med Entomol

$13 \quad 38: 99-107$

14 Kocan KM (1986) Development of Anaplasma marginale in ixodid ticks: coordinated development of a rickettsial organism and its tick host. Pp. 472-505. In: Sauer, J. and Hair, J.A. (Eds). Morphology, Physiology and Behavioral Ecology of Ticks. Ellis Horwood Ltd. Chichester

Kocan KM, Hair JA, Ewing SA (1980) Ultrastructure of Anaplasma marginale Theiler in Dermacentor andersoni Stiles and Dermacentor variabilis (Say). Am J Vet Res 41:1966-

21 Kocan KM, Goff WL, Stiller D, Claypool PL, Edwards W, Ewing SA, Hair JA, Barron SJ.

22 (1992a) Persistence of Anaplasma marginale (Rickettsiales:Anaplasmataceae) in male

23 Dermacentor andersoni (Acari:Ixodidae) transferred successively from infected to 24 susceptible cattle. J Med Ent 29:657-668 
1 Kocan KM, Stiller D, Goff WL, Claypool PL, Edwards W, Ewing SA, McGuire TC, Hair JA, Barron SJ (1992b) Development of Anaplasma marginale in male Dermacentor andersoni transferred from infected to susceptible cattle. Am J Vet Res 53:499-507

Kocan KM, de la Fuente J, Blouin EF, Garcia-Garcia JC (2004) Anaplasma marginale (Rickettsiales : Anaplasmataceae): recent advances in defining host-pathogen adaptations of a tick-borne rickettsia. Parasitol 129:S285-S300

Kocan KM, Yoshioka J, Sonenshine DE, de la Fuente J, Ceraul SM, Blouin EF, Almazán C. (2005) Capillary tube feeding system for studying tick/pathogen interactions of Dermacentor variabilis (Acari: Ixodidae) and Anaplasma marginale (Rickettisales: Anaplasmataceae). $J$ Med Entomol 42:864-874

Lai R, Lomas LO, Jonczy J, Turner PC, Rees HH (2004) Two novel non-cationic defensinlike antimicrobial peptides from haemolymph of the female tick, Amblyomma hebraeum. Biochem J 379:681-685

Lehane MJ, Wu D, Lehane SM (1997) Midgut-specific immune molecules are produced by the blood-sucking insect Stomoxys calcitrans. PNAS USA 94:11502-11507

Ma Y, Creanga A, Lum L, Beachy PA (2006) Prevalence of off-target effects in Drosophila RNA interference screens. Nature 443:359-363

Manzano-Roman R, Almazán C, Naranjo V, Blouin EF, Kocan KM, de la Fuente J (2007) Expression of perilipin in human promyelocytic cells in response to Anaplasma phagocytophilum infection results in modified lipid metabolism. J Med Microbiol, In press Nakajima Y, van der Goes van Naters-Yasui A, Taylor D, Yamakawa M (2002) Antibacterial peptide defensin is involved in midgut immunity of the soft tick, Ornithodoros moubata. Insect Mol Biol 11:611-618 
Nakajima Y, van Naters-Yasui AV, Taylor D, Yamakawa M (2001) Two isoforms of a member of the arthropod defensin family from the soft tick, Ornithodoros moubata (Acari: Argasidae). Insect Biochem Mol Biol 31:747-751

Richardson KC. Jarret L, Finke FH (1960) Embedding in epoxy resins for ultrathin sectioning in electron microscopy. Stain Tech 35:313-323

Rudenko N, Golovchenko M, Edwards MJ, Grubhoffer L (2005) Differential expression of Lxodes ricinus tick genes induced by blood feeding or Borrelia burgdorferi infection. J Med Entomol 42:36-41

Scacheri PC, Rozenblatt-Rosen O, Caplen NJ, Wolfsberg TG, Umayam L, Lee JC, Hughes CM, Shanmugam KS, Bhattacharjee A, Meyerson M, Collins FS (2004) Short interfering RNAs can induce unexpected and divergent changes in the levels of untargeted proteins in mammalian cells. Proc Natl Acad Sci USA 101:1892-1897

Siedz CA, Holko M, de Veer MJ, Silverman RH, Williams BR (2003) Activation of the interferon system by short-interfering RNAs. Natl Cell Biol 5:834-839

Simser JA, Macaluso KR, Mulenga A, Azad AF (2004) Immune-responsive lysozymes from hemocytes of the American dog tick, Dermacentor variabilis, and an embryonic cell line of the Rocky Mountain wood tick, D. andersoni. Insect Biochem Mol Biol 34:1253-1246.

Sonenshine DE (1993) Biology of Ticks, Vol 2. Oxford University Press, New York.

Sonenshine DE, Hynes WL, Ceraul SM, Mitchell, RD, Benzine T (2005) Host blood proteins and peptides in the midgut of the tick Dermacentor variabilis contribute to bacterial control. Exper Applied Acarol 36:207-223

Sukumaran B, Narasimhan S, Anderson JF, DePonte K, Marcantonio N, et al (2006) An Ixodes scapularis protein required for survival of Anaplasma phagocytophilum in tick salivary glands. J Exp Med 203:1507-1517 
1 Todd SM, Sonenshine DE, Hynes WL (2007) Tissue and life-stage distribution of a defensin 2 gene in the Lone Star Tick, Amblyomma americanum. Med Vet Entomol 21:141-147.

3 Tsuji N, Battsetseg, B, Boldbaatar D, Miyoshi T, Xuan X, Oliver JH Jr, Fujisaki K (2007) A. 4 babesial vector tick defensin against Babesia parasites. Infect Immun 75:3633-3640

5 Zhou J, Ueda M, Umemiya R, Battsetseg B, Boldbaatar D, Xuan X, Fujisaki K (2006) A 6 secreted cystatin from the tick Haemaphysalis longicornis and its distinct expression 7 patterns in relation to innate immunity. Insect Biochem. Mol Biol 36:527-535 8 
1 Table 1. Confirmation of gene silencing in midguts, salivary glands and hemolymph from male

2 D. variabilis that were injected with varisin and subolesin dsRNA.

\begin{tabular}{|l|c|c|}
\hline Tick tissue/Collection time & \multicolumn{2}{|c|}{ Expression silencing \pm SD (\%) } \\
\hline & Varisin & Subolesin \\
\hline Midguts after AF & $89.9 \pm 0.1^{*}$ & $90.0 \pm 21.5^{*}$ \\
\hline Midguts after TF & $97.4 \pm 0.1^{*}$ & $99.7 \pm 0.7^{*}$ \\
\hline Salivary glands after TF & $57.9 \pm 0.2^{*}$ & $99.4 \pm 0.9^{*}$ \\
\hline Hemolymph $^{\mathrm{b}}$ & $99.4 \pm 0.5^{*}$ & $\mathrm{ND}$ \\
\hline
\end{tabular}

3

$4 \quad$ Total RNA was extracted from 5 individual ticks from each group and varisin and subolesin

5 expression silencing was determined with respect to control ticks after RNAi. mRNA levels

6 were determined by real-time RT-PCR and compared between dsRNA-treated and control

7

8

9 
2 Table 2. Anaplasma marginale infection levels in D. variabilis males that were injected with

3 varisin and subolesin dsRNAs and then allowed to acquire $A$. marginale infection by feeding on

4 - an experimentally infected calf.

\begin{tabular}{|l|c|c|c|}
\hline Tick tissue & \multicolumn{3}{|c|}{ Average $A$. marginale/tick $\pm \mathrm{SD}^{\mathrm{a}}$} \\
\hline & Varisin RNAi & Subolesin RNAi & Control \\
\hline Midguts after AF & $340 \pm 535^{*}$ & $814 \pm 122$ & $40579 \pm 6993$ \\
\hline Midguts after TF & $1006 \pm 470$ & $1517 \pm 1025$ & $28252 \pm 27788$ \\
\hline Salivary glands after TF & $2 \pm 0^{*}$ & $2 \pm 0^{*}$ & $287 \pm 144$ \\
\hline
\end{tabular}

$5{ }^{a} A$. marginale infection levels in midguts or salivary glands from 5 ticks per group were

6 determined by msp4 PCR and compared between dsRNA-treated and control ticks by Student's

$7 \quad \mathrm{t}$-Test $(* \mathrm{P}<0.05)$. 
Table 3. Varisin expression levels in A. marginale-infected and uninfected D. variabilis. ${ }^{1}$

\begin{tabular}{|l|r|r|r|c|}
\hline \multirow{2}{*}{ Tick tissue } & \multicolumn{2}{|c|}{$\begin{array}{c}\text { Average mRNA levels } \pm \text { SD } \\
\text { (arbitrary units) }\end{array}$} & \multirow{2}{*}{ I/U } & \multirow{2}{*}{ P (Student's t-Test) } \\
\cline { 2 - 3 } & Uninfected & Infected & & \\
\hline Gut & $5.5 \pm 0.6$ & $1.8 \pm 1.5$ & 0.3 & 0.02 \\
\hline Salivary gland & $12.5 \pm 5.2$ & $29.2 \pm 11.1$ & 2.3 & 0.05 \\
\hline
\end{tabular}

${ }^{1}$ Varisin mRNA levels were determined by real-time RT-PCR and compared between dsRNAtreated and control ticks by Student's t-Test $(\mathrm{P}=0.05)(\mathrm{N}=5)$. Amplification efficiencies were normalized against $\beta$-actin using the comparative $\mathrm{Ct}$ method. The infected to uninfected mRNA ratio $(I / U)$ was calculated and showed that defensin mRNA levels significantly decreased in tick guts but increased in tick salivary glands after infection with $A$. marginale. 


\section{Figure}

Figure 1. Light micrographs of tissues in cross sections of ticks that were either injected with varisin dsRNA or elution buffer to serve as controls. (A) Typical large round colonies (C) of $A$. marginale, as described previously by Kocan et al. (1992a,b), were observed in the midguts of the elution buffer injected control ticks. (B) A. marginale colonies (C) observed in the varisin dsRNA males were irregular in shape or appeared to be disrupted in the cytoplasm of gut cells (arrows). (C) Granulated hemocytes $(\mathrm{H})$ were observed in the hemocoel of elution buffer injected control ticks. (D) In contrast to the control ticks, many hemocytes in the varisin dsRNA injected ticks had degranulated (small arrows); (E) Some ticks appeared to be systemically infected with microbes (arrow) which were seen in the midguts lumen (arrow) near gut epithelial cells (GEC) and (F) in spermatogonia (small arrow) among prospermatids (PS). A and B, bars $=10 \mu \mathrm{m} ; C$ and D, bars $=5 \mu \mathrm{m} ; \mathrm{E}$ and $\mathrm{F}$, bars $=10 \mu \mathrm{m}$. 

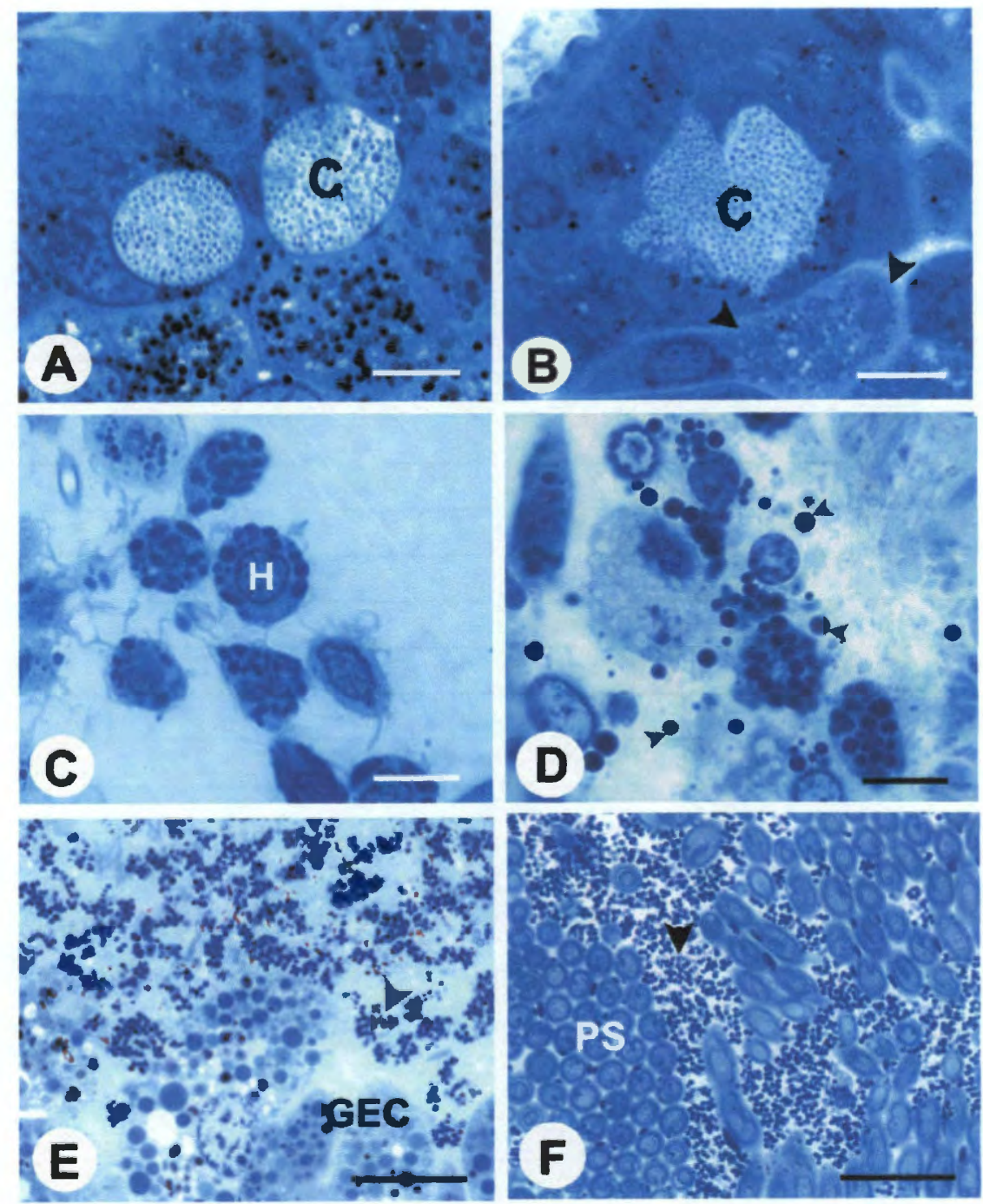